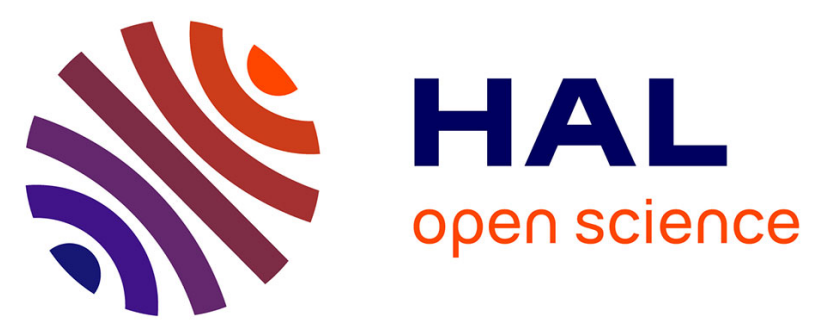

\title{
Persistence and Recycling of Bioinsecticidal Bacillus thuringiensis subsp. israelensis Spores in Contrasting Environments: Evidence from Field Monitoring and Laboratory Experiments
}

Claire Duchet, Guillaume Tetreau, Albane Marie, Delphine Rey, Gilles Besnard, Yvon Perrin, Margot Paris, Jean-Philippe David, Christophe Lagneau, Laurence Després

\section{- To cite this version:}

Claire Duchet, Guillaume Tetreau, Albane Marie, Delphine Rey, Gilles Besnard, et al.. Persistence and Recycling of Bioinsecticidal Bacillus thuringiensis subsp. israelensis Spores in Contrasting Environments: Evidence from Field Monitoring and Laboratory Experiments. Microbial ecology, 2014, 67 (3), pp.576-586. 10.1007/s00248-013-0360-7 . hal-01996644

\author{
HAL Id: hal-01996644 \\ https://hal.science/hal-01996644
}

Submitted on 20 Feb 2019

HAL is a multi-disciplinary open access archive for the deposit and dissemination of scientific research documents, whether they are published or not. The documents may come from teaching and research institutions in France or abroad, or from public or private research centers.
L'archive ouverte pluridisciplinaire HAL, est destinée au dépôt et à la diffusion de documents scientifiques de niveau recherche, publiés ou non, émanant des établissements d'enseignement et de recherche français ou étrangers, des laboratoires publics ou privés. 
Persistence and recycling of bioinsecticidal Bti spores in contrasting environments: evidence from field monitoring and laboratory experiments.

Claire Duchet ${ }^{1, \mathfrak{f}, *}$, Guillaume Tetreau ${ }^{2, \$, *}$, Albane Marie ${ }^{1}$, Delphine Rey $^{3}$, Gilles Besnard ${ }^{3}$, Yvon Perrin $^{1,4}$, Margot Paris ${ }^{2,}$, Jean-Philippe David ${ }^{2}$, Christophe Lagneau ${ }^{1}$, Laurence Després $^{2, \#}$

${ }^{1}$ Entente Interdépartementale de Démoustication du Littoral Méditerranéen, 165 avenue Paul-Rimbaud, F-34184 Montpellier cedex 4, France

10 2Laboratoire d'Ecologie Alpine, LECA-UMR 5553, Université de Grenoble 1, BP 53, 38041

11 Grenoble cedex 09, France.

$12{ }^{3}$ Entente Interdépartementale Rhône-Alpes pour la Démoustication - BP $n^{\circ} 2, F-73310$

13 Chindrieux, France

$14{ }^{4}$ Centre National d'Expertise sur les Vecteurs Centre IRD de Montpellier, 911 avenue

15 Agropolis - BP 64501, F-34394 Montpellier Cedex 5, France

\#Corresponding author : Laurence Després Laboratoire d'Ecologie Alpine, LECA-UMR 5553, Université de Grenoble 1, BP 53, 38041 Grenoble cedex 09, France Tel : +33476635699;

19 Fax : +33476514278 E-mail : laurence.despres@ujf-grenoble.fr;

${ }^{£}$ Present address: Department of Evolutionary \& Environmental Biology, Institute of Evolution, University of Haifa, Haifa 31905 Israel

\$ Present address: Department of Entomology, Cornell University, New York State Agricultural Experiment Station, Geneva, NY 14456, USA

${ }^{\S}$ Present address: ETH Zurich, Department of Plant Ecological Genetics, Switzerland

*These authors contributed equally to the work

Running title: Persistence of Bti spores in the environment 
Sprays of commercial preparations of the bacterium Bacillus thuringiensis subsp. israelensis (Bti) are widely used for the control of mosquito larvae. Despite an abundant literature on Bti field efficiency on mosquito control, few studies have evaluated the fate of spores in the environment after treatments. In the present article, two complementary experiments were conducted to study the effect of different parameters on Bti persistence and recycling, in field conditions and in the laboratory. First, we monitored Bti persistence in the field in two contrasting regions in France: the Rhône-Alpes region, where mosquito breeding sites are temporary ponds under forest cover with large amounts of decaying leaf matter on the ground, and the Mediterranean region characterized by open breeding sites such as brackish marshes. Viable Bti spores can persist for months after a treatment, and their quantity is explained both by the vegetation type and by the number of local treatments. We found no evidence of Bti recycling in the field. Then, we tested the effect of water level, substrate type, salinity, and presence of mosquito larvae on the persistence/recycling of Bti spores in controlled laboratory conditions (microcosms). We found no effect of change in water level or salinity on Bti persistence over time ( 75 days). Bti spores tended to persist longer in substrates containing organic matter compared to sand-only substrates. Bti recycling only occurred in presence of mosquito larvae, but was unrelated to the presence of organic matter.

Keywords: Bacillus thuringiensis subsp israelensis; persistence; field; recycling; mosquito 


\section{Introduction}

The bioinsecticide Bacillus thuringiensis subsp. israelensis (Bti) is often considered a safe and environmentally-friendly alternative to chemical insecticides and it is increasingly used worldwide for mosquito control [1]. Its toxicity for mosquito larvae is conferred by a toxic crystal produced during the sporulation of the bacterium [2]. Recently, a European directive on biocidal products has made $B t i$ one of the few larvicides authorized for mosquito control in Europe. Bti is usually sprayed in breeding sites as a suspension of spores and crystals that kill mosquito larvae by gut disruption after ingestion [3]. It is generally characterized by low-level persistence in the environment despite a huge literature reporting that its residual insecticidal activity can range from a few days up to several months [4-6]. Several parameters have been reported to have an impact on Bti toxicity such as UV light, temperature, pollution, salinity or the presence of organic matter [2, 7-10]. In contrast, little is known about the parameters that could influence the persistence and the possible recycling of spores in the environment. Although several authors have reported a recycling of Bti in cadavers of mosquito larvae in controlled or simulated conditions [11-13] and of Bti-killed mosquito larvae to scavenging larvae [14], evidence for recycling under natural field conditions is scarce (but see [15, 16]). One of these recycling events has been described in mosquito breeding sites from the French Rhône-Alpes region in which leaf litter sampled several months after a treatment contained high amounts of spores and toxins and exhibited a high toxicity for mosquito larvae $[15,17$, 18]. Another case of Bti recycling has been reported in simulated conditions in water tanks, which are typical breeding sites for mosquitoes in urban areas [16]. Understanding the parameters that favour Bti persistence and recycling in various conditions of treatments and environments (from large-scale spraying across breeding sites in the field to local applications in water tanks in urban areas) is of high importance to ensure a sustainable and integrated use of this widely used bioinsecticide.

In order to characterize these parameters, we first monitored persistence of spores throughout the operational season in mosquito breeding sites from two contrasting French regions representative of a large range of treated mosquito breeding sites and of different operational practices. Bti has been sprayed in the French Rhône-Alpes region for several decades, but it only replaced the organophosphate Temephos ten years ago in the French Mediterranean region. These two regions strongly differ both in the type of mosquito breeding sites (woodland freshwater temporary ponds versus large open areas of brackish marshes), and in the operational treatments performed (Vectobac ${ }^{\circledR} \mathrm{WG}$, solid formulation applied mainly by backpack spraying versus Vectobac ${ }^{\circledR} 12 \mathrm{AS}$, liquid formulation sprayed by aircraft).

Then, we tested the effect of selected parameters on Bti persistence in laboratory controlled conditions (microcosms). The influence of salinity and substrate type (sand or organic matter) were tested as they are two main parameters differing between the two French regions previously investigated. Moreover, considering that mosquito breeding sites often experience drying/watering episodes, we also tested the effect of water level fluctuation on spore persistence. As B. thuringiensis is an entomopathogen [19], presence of insect hosts could influence its persistence and recycling. Therefore, we tested the effect of the presence of mosquito larvae in two different conditions: with an organic matter substrate and in water only, in order to simulate the two situations where Bti recycling has been reported so far [16, 17]. All the results are discussed regarding to Bti persistence in the environment and its consequences on field treatments and management strategies. 


\section{Field sampling}

106 The field study was performed in two different areas in France, where Bti is applied for mosquito control: Rhône-Alpes and Mediterranean region, during 3 years (2009-2011). A total of 28 sites were sampled, including 16 in the Rhône-Alpes region and 12 in the Mediterranean region (Fig. 1). Samplings were performed before the first Bti treatment of the year, two days after, and then 90 and 180 days after the first treatment, corresponding to the middle and end of the mosquito control season, respectively. In the Rhône-Alpes region, most sites were temporary ponds under forest cover (Alnus, Fraxinus, Quercus, Salix) with large amounts of decaying leaf litter accumulating on the ground, whereas Mediterranean study sites were marshes with variable hydroperiod and salinity and a vegetation cover either dominated by Salicornia (salt marshes), Scirpus (bulrush beds), Juncus (rush beds), or Phragmites (reed beds). Characteristics of the sites are summarized in Table 1. They were classified according to the vegetation cover (low: direct UV light exposure, or dense: no or limited light exposure), and the Bti treatment history during the study season (treated or untreated, and total number of treatments). For each site and each date, two superficial soil samples (about $5 \mathrm{~g}$ each, $<1 \mathrm{~cm}$ depth, including organic litter when present) were collected. Depending on the amount of leaf litter present in the collected samples (de visu evaluation), they were classified in three categories: null (inorganic substrate only), low (both organic and inorganic substrate present in the sample), or high (leaf litter only: this was characteristic of all forest sites). Samples were dried at $50^{\circ} \mathrm{C}$ for $48 \mathrm{~h}$, powdered with a planetary ball mills (PM100, Retsch ${ }^{\circledR}$, Haan, Germany), and stored at $-20^{\circ} \mathrm{C}$ in sterile vials until use.

\section{Microcosm experiments}

Two experiments were performed in $130 \mathrm{~L}$ glass aquaria (microcosms) set in the laboratory at room temperature (approximately $22^{\circ} \mathrm{C}$ ), in a light-dark regimen of 16:8. The first experiment was aimed at evaluating the influence of change in organic matter, water level, and salinity on Bti persistence (Fig. 2A), while the second experiment was designed to evaluate the effect of the presence of mosquito larvae on Bti recycling in presence of organic matter or in water only (Fig. 2B).

\section{Experiment 1: Effect of change in water level, salinity and substrate on Bti persistence (Fig.}

\section{A)}

Twenty microcosms were filled with $8 \mathrm{~cm}$ of autoclaved sand and clay 30\% (inorganic substrate) and half of them (ten microcosms) were added with $5 \mathrm{~cm}$ of compost and $5 \mathrm{~cm}$ of leaf litter collected in an untreated forest breeding site in Rhône-Alpes (organic substrate, conditions a-e). Sixty-five litres of tap water were added in each microcosms (hardness 15 to 20 terahenry $(\mathrm{TH}), \mathrm{pH}=7)$ to reach $20 \mathrm{~cm}$ water level. Four environmental conditions were examined for each substrate: salinity at 0 g.L $\mathrm{L}^{-1}$ (conditions a,f), salinity at $40 \mathrm{~g} . \mathrm{L}^{-1}$ (corresponding to the maximum salinity in a marsh pool in the Mediterranean area; conditions $\mathrm{b}, \mathrm{g}$ ), water level maintained at $20 \mathrm{~cm}$ (conditions d,i), and water level fluctuating from 20 to 0 cm weekly (meaning a week with $20 \mathrm{~cm}$ followed by a week with $0 \mathrm{~cm}$; conditions e,j). Microcosms were treated with Bti at $5 \mathrm{~L}^{-\mathrm{ha}^{-1}}$ (nominal concentration for $20 \mathrm{~cm}$ water depth: $2.5 \mu \mathrm{L} . \mathrm{L}^{-1}$ ) and each modality was performed in 2 replicates. The $5{\mathrm{~L} . h a^{-1}}^{-1}$ dose corresponds to twice the recommended rate for aerial treatments [20]. Four untreated microcosms remained as controls, two with inorganic substrate (condition h) and two with organic-enriched substrate (condition c).

\section{Experiment 2: Effect of the presence of larvae on Bti persistence and recycling (Fig. 2B)}


Nine microcosms were filled with organic substrate and $65 \mathrm{~L}$ of tap water (hardness 15 to 20 $\mathrm{TH}, \mathrm{pH}=7$; conditions a-e), including one untreated microcosm as a control (condition c). Nine microcosms were only filled with water (conditions $\mathrm{f}-\mathrm{j}$ ), including one untreated microcosm as a control (condition h). In half of the microcosms (four microcosms per substrate), 5000 third-instar mosquito larvae were added before Bti treatment (conditions $\mathrm{d}, \mathrm{e}, \mathrm{i}, \mathrm{j})$. Such a high number of larvae was chosen in order to cover the entire substrate with dead larvae after treatment. Larvae were all dead within $24 \mathrm{~h}$. The laboratory "Bora Bora" strain of Aedes aegypti was used for the experiment. Larvae were previously reared in tap water and fed with standard amounts of larval food (dry dog food) in standard laboratory conditions $\left(27^{\circ} \mathrm{C}\right.$, light-dark regimen of $16: 8$, and $70 \%$ relative humidity) during 5 days before the experiment. Two Bti concentrations were used for each condition: 5 L.ha ${ }^{-1}$ (conditions a,d,f,i) and $25 \mathrm{~L} . h a^{-1}$ (conditions b,e,g,j) (nominal concentration for $20 \mathrm{~cm}$ water depth: $2.5 \mu \mathrm{L} . \mathrm{L}^{-1}$ and $12.5 \mu \mathrm{L} . \mathrm{L}^{-1}$, respectively). Each modality was performed in 2 replicates, and two microcosms without larvae remained as controls (conditions c,h).

\section{Microcosms Bti treatment and sampling}

Microcosms were allowed to stabilize for $96 \mathrm{~h}$ before Bti application. All the microcosms (except controls) were treated with a commercial Bti formulation (Vectobac ${ }^{\circledR} 12 \mathrm{AS}$; Valent Bioscience Ins., Libertyville, IL, USA; $1200 \mathrm{ITU} / \mathrm{mg}$, suspension concentrate), at $2.5 \mu \mathrm{L} . \mathrm{L}^{-1}$ (corresponding to $5 \mathrm{~L}^{\mathrm{h} \mathrm{ha}^{-1}}$ ) to evaluate the effect of substrate, salinity and change in water level on Bti persistence (experiment 1), and at two different Bti-concentrations $\left(2.5 \mu \mathrm{L} . \mathrm{L}^{-1}\right.$ and $12.5 \mu \mathrm{L} . \mathrm{L}^{-1}$ corresponding to 5 and $25 \mathrm{~L}^{-h^{-1}}{ }^{-1}$ ) to evaluate the effect of mosquito larvae on $B t i$ persistence (experiment 2). Monitoring started just before the Bti treatment (day 0), and was carried out until 75 days after insecticide spraying. Sampling was performed on days 0,1 , $2,7,14,21,28,45,60$, and 75 .

In microcosms with substrate, two samples consisting of $5 \mathrm{~g}$ of substrate were sampled at each sampling date. They were dried and powdered as previously described and stored at $20^{\circ} \mathrm{C}$ until use. In microcosms without substrate, water was stirred, and twice $250 \mathrm{~mL}$ of water were taken, without subsequent refilling of the microcosm. Water samples were filtered through a fiberglass filters $\left(0.2 \mu \mathrm{m}\right.$ pores, Isopore ${ }^{\mathrm{TM}}$ membrane filters, Millipore, Billerica, MA, USA) and filters were stored at $-20^{\circ} \mathrm{C}$ in sterile vials.

On each sampling date, the water temperature, dissolved oxygen, salinity and $\mathrm{pH}$ were measured in every microcosm at ca. $5 \mathrm{~cm}$ below the water surface, using portable apparatuses (Wissenschaftlich-Technische-Werkstätten -WTW, Champagne au Mont d'Or, France) to control the stability of the systems. Collected data are not presented as they remained stable during the course of the experiment.

\section{Colony counting}

One gram from each dried sample (or filter) was suspended into $10 \mathrm{~mL}$ of TSB (Trypticase Soy Broth) for $60 \mathrm{~min}$. The suspension was then heated to $80^{\circ} \mathrm{C}$ for $30 \mathrm{~min}$, such that only bacterial spores survived $[15,21]$. Tenfold dilutions were made in TSB $\left(10^{-1}\right.$ and $\left.10^{-2}\right)$, and $200 \mu \mathrm{L}$ of each dilution were plated on nutrient agar in duplicate. Plates were incubated at 30 $\pm 2^{\circ} \mathrm{C}$ for $24 \mathrm{~h}$ under aerobic conditions. Bacillus colonies were identified and counted by their morphological appearance. Colonies that were beige, with irregular edges and an "ice crystal" appearance were considered as Bacillus thuringiensis [22]. To verify these colonies were indeed Bacillus thuringiensis subsp. israelensis we randomly picked 22 colonies and bacilli were incubated with rabbit antiserum specific for H14 serotype (kindly provided by Christina Nielsen-Leroux) during 1 hour at room temperature. After 3 washes with PBS and $1 \mathrm{~h}$ incubation with FITC-conjugated goat anti-rabbit Ig (Southern biotech, USA), stained bacteria were observed using fluorescent microscopy (BX41 Olympus, France) as described 
203 in [15]. All the colonies identified morphologically as being Bti were detected as Bti by

204 immunology.

\section{Data analysis}

207 Data normality was tested using Shapiro-Wilk test, and the homogeneity of variances 208 between treatments was tested using Bartlett's test. Because Bti colony forming units (CFU) 209 counts were not normally distributed, but followed a quasi-poisson distribution, we first 210 performed non-parametric tests (Mann-Whitney and Kruskal Wallis tests) on each separate 211 explanatory factor. Because non-parametric tests do not allow testing simultaneously different 212 factors and their interactions, we then performed generalized linear models adapted to our 213 non-normally distributed, overdispersed, count datasets (quasi-poisson family, log link). In 214 experiments 1 and 2, the microcosm effect was considered as a random factor. Control 215 microcosms (without Bti) that contained no colonies were not included in further statistical 216 analysis. All tests were performed using R software version 2.15.1 [24]. Significance was 217 accepted at $\alpha=0.05$ for all tests. 


\section{Field study}

Most of the collected field samples did not contain any viable Bti spores, and some samples from untreated sites contained viable Bti spores. However, treated sites contained an order of magnitude more Bti viable spores than untreated sites (Fig. 3A), and the treatment effect explained $7.5 \%$ of the total deviance (Table 2). Furthermore, CFU counts and the total number of treatments in a given site were positively correlated (Spearman's correlation coefficient $r_{s}=0.22, p=310^{-7}$ ). Vegetation type explained $8.8 \%$ of the total deviance, with more viable spores found in meadows, rush beds and forests, than in reed beds, salt marshes and bulrush beds (Fig. 3B). In order to disentangle the respective roles of insecticide pressure (total number of treatments), vegetation cover, and organic matter present on the ground to explain Bti spore persistence, a generalized linear model including the three factors and all possible interactions as explanatory variables was fitted to the number of colonies counted (Table 3). The factor 'Vegetation Cover' was significant and explained $1.7 \%$ of total deviance, with more Bti spores found under a dense vegetation cover. Although the factor 'Insecticide pressure' alone was not significant, the interactions between 'Insecticide pressure' and 'Leaf litter' factors, and between 'Insecticide pressure', 'Leaf litter'and 'Vegetation Cover' were significant and explained respectively $17 \%$ and $2.5 \%$ of total deviance. More viable Bti spores were found with increasing number of treatments in sites with high leaf litter content, corresponding to forest sites characteristics of the Rhône-Alpes region; the correlation between the number of Bti treatments and CFU was positive in both regions, but only significant in the Rhône-Alpes region (Spearman's correlation coefficient $r_{s}$ $=0.42, p=7.2510^{-13}$ in the Rhône-Alpes region and $r_{s}=0.11, p=0.09$ in the Mediterranean region).

\section{Microcosm study}

From day 0 to day 7, Bti viable spores were significantly more abundant in the microcosms containing an organic substrate (compost and leaf litter) than in microcosms with inorganic substrate only (mixture of sand and clay only) (Fig. 4A; date by date analysis, Mann-Whitney tests, all $p<0.001)$. However, this effect was no longer significant after day 7 due to the high variability between replicates (date by date analysis, Mann-Whitney tests, all $p>0.1$ ). There was no significant effect of water salinity (Fig. 4B) or water level fluctuation (Fig. 4C) on Bti persistence (date by date analysis, all Mann-Whitney tests $p>0.05$ ). In order to determine which factors and combination of factors best explain the Bti spore persistence patterns observed over time, we performed a generalized linear mixed model (GLMM) including sampling dates, substrate type (inorganic or organic), water salinity $\left(40 \mathrm{~g} . \mathrm{L}^{-1}\right.$ or 0 g. $\mathrm{L}^{-1}$ ), and water level (maintained or fluctuating), as fixed factors, and microcosm as random effect to explain the number of Bti colonies counted (Table 3). Only the factors 'Date' and 'Substrate' had a significant effect ( $p=2.347 \cdot 10^{-07}$ and $p=0.0355$, respectively), which is due to a significant increase in CFU.g ${ }^{-1}$ observed just after treatment (day 1) followed by a nonsignificant decrease in CFU.g ${ }^{-1}$ from day 2 to the end of the experiment (day 75). The secondand third-order interactions were not significant (Table 4).

Change in Bti colonies abundance over time with or without mosquito larvae, at two different Bti-concentrations, was monitored (Fig. 5). The number of Bti colonies was significantly higher in presence of mosquito larvae from day 21 to the end of the study period, except at day 60 (Kruskal-Wallis test, $p>0.05$ ), irrespective of the Bti concentration applied. This is in contrast to the microcosms without mosquito larvae where Bti colonies remained low for both Bti concentrations. 
269 GLMM including sampling dates, substrate type (organic substrate with leaf litter, or water 270 only), presence or absence of mosquito larvae, and concentration (concentration of Bti: 2.5 or $12.5 \mu \mathrm{L} . \mathrm{L}^{-1}$ ) as fixed factors and microcosm as random factor was fitted to the number of colonies counted (Table 5). The factors 'Date' and 'Larvae' were highly significant, with a significant increase in CFU just after treatment (day 1 ) followed by a maximal increase by two orders of magnitude in CFU after 28-45 days in presence of larvae. Although there was no effect of 'Substrate' or 'Treatment' factors alone, there were significant interactions between 'Date' and 'Substrate' (with maximum CFU counts at day 28 in organic matter and at day 45 in water), between 'Date' and 'Treatment' and between 'Substrate' and 'Concentration' factors. All other interactions between factors were not significant (Table 5). 


\section{Fate of Bti spores in the field}

284 The number of viable Bti spores recovered from field samples was highly variable, ranging from 0 up to $10^{5}$, with an average of $10^{4} \mathrm{CFU} \cdot \mathrm{g}^{-1}$. This is comparable to previous studies, with $10^{4}-10^{6} \mathrm{CFU} . \mathrm{g}^{-1}$ in a temporary flooded salt marsh in the Mediterranean region treated twice with Bti during the season [13], and $10^{3}-10^{6} \mathrm{CFU} \cdot \mathrm{g}^{-1}$ in a natural wetland treated for 22 years in Switzerland $[8,12]$. In a given site, the number of CFU.g ${ }^{-1}$ found was correlated to the total number of treatments performed the year of the study. The same pattern was observed in a Swiss natural wetland where Bti abundance was explained by the number of treatments of the year, with no evidence for a cumulative effect from one year to the next [12]. These results suggest that Bti spores can persist for months during the treatment season (from spring to autumn), but the amount of viable overwintering spores is too low to significantly affect the amount of spores the following year. In some of our study sites, viable Bti spores were found before the first treatment occurred, as well as in some untreated sites, but in much lower amount than in treated sites. These spores might be either overwintering spores from treatments performed the year before, or indigenous Bti strains (unrelated to Bti treatment). Whatever the origin of these Bti spores, Bti treatment significantly increased the number of spores locally recovered.

Our results revealed that vegetation cover was a factor affecting Bti spores persistence, with more colonies found in dense compared to low cover sites (2344 versus $1196 \mathrm{CFU} . \mathrm{g}^{-1}$ in dense and low cover sites, respectively). Considering that UV light is known to decrease Bti efficacy [18], this result suggests that the presence of dense vegetation cover may protect the integrity of Bti spores by filtering UV light. This protective effect seems to compensate a possible reduced amount of Bti reaching the ground under dense vegetation cover. More than vegetation cover, the main factor explaining Bti spore persistence in the field was the interaction between insecticide pressure and leaf litter content on the ground, explaining up to $17 \%$ of total deviance. More precisely, viable Bti spore number was positively correlated to the number of treatments only in the Rhône-Alpes region, where all sites are characterized by dense vegetation cover and high litter content. By contrast, in sites of the Mediterranean region, with no or low amounts of organic matter on the soil, insecticide pressure and $\mathrm{CFU}$ counts were not correlated, suggesting that in the absence of organic matter on the ground, there is no accumulation of spores throughout the treatment season. The leaf litter present on the ground may favor Bti spore accumulation on the substrate surface by protecting them from being flooded away, and might also have a role in UV protection. Furthermore, the interaction effect is to be related not only to difference in the vegetation cover and leaf litter content on the ground between the two regions, but also to difference in the intensity of insecticide pressure; the maximum number of treatments in one single site is 25 in Mediterranean region, compared to 6 in Rhône-Alpes region. Such difference can be explained both by the treatment strategy (i.e. treatments for mosquito control are applied only when mosquito larvae are observed) and the nature of the treated wetlands. Indeed, most mosquito breeding sites from the Mediterranean region are highly temporary flooded areas with a succession of drying/watering events over the season, requiring many treatments per year for one site. Breeding sites from the Rhône-Alpes region generally experience less hydrological variations, resulting in a lower insecticide pressure than in the Mediterranean region. Moreover, the Mediterranean mosquito control agency sprays Bti in large open areas by plane while most breeding sites from the Rhône-Alpes region are small woodland temporary ponds sprayed by walking agents.

\section{Effect of salinity and water level fluctuation on Bti spores persistence}


Salinity was recently shown to have a small but significant negative impact on the toxicity of Bti to Ae. aegypti and Anopheles gambiae larvae [23, 24] but the nature of the interaction between salinity and $B t i$ is still unknown. No study designed to evaluate the impact of salinity on Bti spore persistence in controlled conditions has been published thus far. Our results show that Bti spore persistence is not influenced by salinity. Therefore, salinity may act directly on mosquito larvae, maybe by affecting their feeding rate, or on the crystal, potentially affecting toxin stability or tridimensional toxins conformation, but it has no direct effect on the viability of Bti spores.

Many mosquito breeding sites are temporary pools subjected to frequent episodes of drying/watering. A previous study showed that the fluctuation of the water level had no significant impact on Bti toxins persistence in leaf litter [17] and the present study shows that it also has no effect on spore persistence. Altogether, these results suggest that the water level fluctuation often experienced by mosquito breeding sites does not affect directly the efficacy and persistence of $B t i$.

\section{Parameters influencing Bti recycling}

Although Bti spores can persist for months in soil [22, 25], Bti is an insect pathogen and its vegetative cells cannot proliferate in soils without a suitable insect host $[19,26]$. Recycling of $B t i$ in larval cadavers (i.e. germination, proliferation and sporulation) in the laboratory and in simulated habitats have been reported by several authors [11-13] but despite an intensive and wide scale use of commercial formulations that include both viable spores and toxic crystals, evidence for Bti recycling under natural field conditions is scarce. To our knowledge, only two reports of Bti recycling in field conditions have been documented; the first one occurred in a site rich in organic matter in the Rhône-Alpes region where a significant increase of larval toxicity [18], spore number [15] and toxin quantity [17] was observed several months after Bti treatment. However, despite the 3-years large-scale sampling performed in the present study, we were not able to detect any new case of recycling in the field, neither in the Rhône-Alpes region, nor in the Mediterranean region. The design of our field study was not optimal to detect Bti recycling as we monitored operational sites under continuous insecticide pressure throughout the season, with the last sampling occurring one month after the last treatment. To demonstrate that recycling occurred in the field would require monitoring sites for a longer time after the last treatment. This was done in our experimental design where one single Bti treatment was performed, followed by regular sampling and spore counting up to 75 days after treatment. The second case of recycling reported in the literature [16] was observed in water containers, which represents a typical mosquito breeding sites in Bti-treated urban areas. In this study, recycling was evidenced by observing a 100 -fold increase of bacterial concentration (to reach $10^{6}$ spores per $\mathrm{mL}$ ) from day 30 to day 180 after treatment [16].

By reproducing these two conditions where Bti recycling has been observed (with substrate rich in organic matter and in water only), we showed that Bti recycling occured only in presence of mosquito larvae, both in organic rich and water microcosms. Evidence for recycling is given by the increase by 2 orders of magnitude in the CFU counts 28-45 days after treatment, with an increase of up to $2.510^{5} \mathrm{CFU} . \mathrm{g}^{-1}$ as compared to an average of $10^{3}$ CFU . $\mathrm{g}^{-1}$ just after treatment and throughout the experiment ( 75 days) in microcosms without larvae. This 30-days delay between Bti treatment and recycling seems to be the time required for the full Bti life cycle to complete; that is, the time required for the toxins to be ingested by larvae, activated in the insect alkaline midgut, to bind to specific receptors and disrupt the midgut epithelium, to penetrate into the insect tissues, germinate, and proliferate as vegetative cells [3]; sporulation is a secondary process (when nutrients from larval tissues are no more available) which involves several stages including formation of a composite proteic crystal 
and of a forespore, formation of exosporium, cortex and spore coats, and spore maturation 381 [27].

382 The same pattern of recycling was found with the two Bti concentrations tested, indicating that the first concentration, which corresponds to twice the recommended operational dose, was sufficient to kill all the larvae present in the aquarium, leading to a saturation of the resources available. Therefore, increasing the quantity of Bti sprayed did not result in an increase of the overall bacterial division success. However, the significant interaction observed between dates and $B t i$ concentration reflects that $B t i$ was more rapidly ingested by larvae when it was provided in excess. A new experiment allowing measuring the uptake and quantity of $B t i$ in larvae over time must be designed to validate this hypothesis, which could not be tested in the present study due to the fast decomposition of larval cadavers (in 24 to 48 hours).

\section{The effect of the organic matter}

The organic matter is known to be a major factor influencing both the efficacy of Bti and the persistence of its mosquitocidal activity. Indeed, Bti toxicity was shown to decrease with water turbidity and in organic rich habitats because toxins are rapidly denatured and/or bound to organic matter [2]. Furthermore, it has recently been shown that Bti toxins behave differently in presence of leaf litter, which may partly explain the rapid loss of toxicity observed in presence of leaf litter $[10,17]$. In contrast to toxin persistence, the present study shows that organic matter (including leaf litter) is a factor favouring Bti spore persistence. Indeed, both microcosm and field experiments revealed a positive effect of organic matter on spore persistence. The presence of leaf litter on the substrate may immobilize Bti spores and prevent them from being flowed away, favouring their accumulation throughout repeated treatments. Leaf litter might also contribute to protect $B t i$ spores from direct UV light.

No effect of the substrate was observed on Bti recycling in larvae as similar recycling patterns were observed in microcosms with or without organic matter. The significant interaction between substrate and dates is only due to the fact that more spores were found just after treatment in the microcosms with organic matter, confirming the positive effect of organic matter on spore persistence.

Altogether, these results show that the organic matter has a contrasting effect on Bti persistence, decreasing its efficacy and the persistence/bioavailability of its toxins [10] but increasing the persistence of the spores over time (present study). This is consistent with previous studies conducted on Btk (Bacillus thuringiensis subsp kurstaki) where no correlation was found between spores and toxins recovered in soils after spraying [28]. Crystals and spores are two highly different structures; the first being a conglomerate of proteins responsible for toxicity, while the latter is a survival form of the bacteria. Therefore, it is somewhat unsurprising that their interaction with the complex structure of the organic matter differ. Finally, although organic matter by itself does not directly promote $B t i$ recycling in absence of mosquito larvae, the presence of organic matter increased spores persistence, and therefore the probability for Bti spores to be ingested by mosquito larvae and to proliferate.

\section{Conclusion}

Our results reveal that viable Bti spores can persist for months in the environment after a treatment, and that their quantity is explained both by the number of local treatments and by the type of vegetation. Salinity and water level fluctuation did not influence Bti spores persistence in controlled conditions, while the presence of organic matter was a major parameter affecting spores persistence both in the field and in the laboratory. Finally, no evidence for Bti recycling was found in the field; but we experimentally showed that the 
presence of larvae is necessary for Bti recycling, irrespective of the presence of organic matter.

\section{Acknowledgements}

This work was founded by the French National Research Agency (ANR, project ANR-08CES-006-01 DIBBECO). We thank R. Foussadier, S. Reynaud, S. Veyrenc, A. Bonin, E. Coissac and C. Melodelima (members of the DIBBECO Consortium) for helpful discussions on the Bti persistence part of the DIBBECO project, C. Nielsen-LeRoux for providing the rabbit antiserum specific for H14 serotype, S. Perigon and M. Fabris for technical help, and G. Moraru for correcting our english.

\section{References}

1. Abdul-Ghani R, Al-Mekhlafi AM, Alabsi MS (2012) Microbial control of malaria: Biological warfare against the parasite and its vector. Acta Tropica 121: 71-84.

2. Lacey LA (2007) Bacillus thuringiensis serovariety israelensis and Bacillus sphaericus for mosquito control. Journal of the American Mosquito Control Association 23: 133-163.

3. Vachon V, Laprade R, Schwartz JL (2012) Current models of the mode of action of Bacillus thuringiensis insecticidal crystal proteins: a critical review. Journal of Invertebrate Pathology 111: 1-12.

4. Mulla MS, Chaney JD, Rodchareon J (1993) Elevated dosages of Bacillus thuringiensis var. israelensis fail to extend control of Culex larvae. Bulletin of Society For Vector Ecology 18: 125-132.

5. Ritchie SA, Rapley LP, Benjamin S (2010) Bacillus thuringiensis var. israelensis (Bti) provides residual control of Aedes aegypti in small containers. Am J Trop Med Hyg 82: 1053-1059.

6. Vilarinhos PTR, Monnerat R (2004) Larvicidal persistence of formulations of Bacillus thuringiensis var. israelensis to control larval Aedes aegypti. Journal of the American Mosquito Control Association 20: 311-314.

7. Christiansen JA, McAbee RD, Stanich MA, DeChant P, Boronda D, Cornel AJ (2004) Influence of temperature and concentration of $\operatorname{Vectobac}((\mathrm{R}))$ on control of the saltmarsh mosquito, Ochlerotatus squamiger, in Monterey County, California. Journal of the American Mosquito Control Association 20: 165-170.

8. Boisvert M, Boisvert J, Aubin A (2001) Factors affecting residual dosages of two formulations of Bacillus thuringiensis subsp israelensis tested in the same stream during a 3-year experiment. Biocontrol Science and Technology 11: 727-744.

9. Margalit J, Bobroglo H (1984) The effect of organic materials and solids in water on the persistence of Bacillus-thuringiensis var israelensis serotype-H-14. Journal of Applied Entomology 97: 516-520.

10. Tetreau G, Stalinski R, Kersusan D, Veyrenc S, David JP, Reynaud S, Despres L (2012) Decreased Toxicity of Bacillus thuringiensis subsp. israelensis to Mosquito Larvae after Contact with Leaf Litter. Applied and Environmental Microbiology 78: 5189-5195.

11. Aly C, Mulla MS, Federici BA (1985) Sporulation and toxin production by Bacillusthuringiensis var israelensis in cadavers of mosquito larvae (Diptera, Culicidae). Journal of Invertebrate Pathology 46: 251-258.

12. Khawaled K, Bendov E, Zaritsky A, Barak Z (1990) The fate of Bacillus-thuringiensis var israelensis in Bacillus-thuringiensis var israelensis-killed pupae of Aedes-aegypti. Journal of Invertebrate Pathology 56: 312-316. 
13. Boisvert M, Boisvert J (1999) Persistence of toxic activity and recycling of Bacillus thuringiensis var. israelensis in cold water: Field experiments using diffusion chambers in a pond. Biocontrol Science and Technology 9: 507-522.

14. Zaritsky A, Khawaled K (1986) Toxicity in carcasses of Bacillus thuringiensis var. israelensis-killed Aedes aegypti larvae against scavenging larvae: implications to bioassay. Journal of the American Mosquito Control Association 2: 555-559.

15. Tilquin M, Paris M, Reynaud S, Despres L, Ravanel P, Geremia RA, Gury J (2008) Long Lasting Persistence of Bacillus thuringiensis subsp. israelensis (Bti) in Mosquito Natural Habitats. PLoS ONE 3: e3432.

16. de Melo-Santos MAV, de Araujo AP, Rios EMM, Regis L (2009) Long lasting persistence of Bacillus thuringiensis serovar. israelensis larvicidal activity in Aedes aegypti (Diptera: Culicidae) breeding places is associated to bacteria recycling. Biological Control 49: 186-191.

17. Tetreau G, Alessi M, Veyrenc S, Périgon S, David JP, Reynaud S, Després L (2012) Fate of Bacillus thuringiensis subsp. israelensis in the field: evidence for spore recycling and differential persistence of toxins in leaf litter. Applied and Environmental Microbiology 78: 8362-8367.

18. David JP, Rey D, Cuany A, Bride JM, Meyran JC (2002) Larvicidal properties of decomposed leaf litter in the subalpine mosquito breeding sites. Environ Toxicol Chem 21: 62-66.

19. Raymond B, Johnston PR, Nielsen-LeRoux C, Lereclus D, Crickmore N (2010) Bacillus thuringiensis: an impotent pathogen? Trends Microbiol 18: 189-194.

20. Ministère Français de l'Agriculture et de l'Agroalimentaire (2012) e-phy: Le catalogue des produits phytopharmaceutiques et de leurs usages des matières fertilisantes et des supports de culture homologués en France. e-phy.agriculture.gouv.fr.

21. Marigo G, Meyran JC, Tilquin M (2002) Matière active insecticide, procédé de préparation et utilisations. Patent \#FR20020016544 20021223, Université de Grenoble, France.

22. Hajaij M, Carron A, Deleuze J, Gaven B, Setier-Rio ML, Vigo G, Thiery I, NielsenLeRoux C, Lagneau C (2005) Low persistence of Bacillus thuringiensis serovar israelensis spores in four mosquito biotopes of a salt marsh in southern france. Microbial Ecology 50: 475-487.

23. Jude PL, Tharmasegaram T, Sivasubramaniyam G, Senthilnanthanan M, Kannathasan S, Raveendran S, Ramasamy R, Surendran SN (2012) Salinity-tolerant larvae of mosquito vectors in the tropical coast of Jaffna, Sri Lanka and the effect of salinity on the toxicity of Bacillus thuringiensis to Aedes aegypti larvae. Parasites \& Vectors 5:269.

24. Osborn FR, Herrera MJ, Gomez CJ, Salazar A (2007) Comparison of two commercial formulations of Bacillus thuringiensis var. israelensis for the control of Anopheles aquasalis (Diptera : Culicidae) at three salt concentrations. Memorias do Instituto Oswaldo Cruz 102: 69-72.

25. Guidi V, Patocchi N, Luethy P, Tonolla M (2011) Distribution of Bacillus thuringiensis subsp israelensis in Soil of a Swiss Wetland Reserve after 22 Years of Mosquito Control. Applied and Environmental Microbiology 77: 3663-3668.

26. Glare TR, O'Callaghan M (2000) Bacillus thuringiensis: Biology, Ecology and Safety. John Wiley \& Sons, Chichester, UK

27. Ibrahim MA, Griko N, Junker M, Bulla LA (2010) Bacillus thuringiensis: a genomics and proteomics perspective. Bioengineered bugs 1: 31-50. 
528 28. Vettori C, Paffetti D, Saxena D, Stotzky G, Giannini R (2003) Persistence of toxins and cells of Bacillus thuringiensis subsp kurstaki introduced in sprays to Sardinia soils. Soil Biology \& Biochemistry 35: 1635-1642. 
533 Table 1. Main characteristics of the sites studied. The region, name of site, year of

534 sampling, treatment modality, the main vegetation type and vegetation cover (dense or

535 low) are indicated. Insecticide pressure (number of treatments) and amount of leaf litter

536 in soil samples are also indicated. The code indicated in the third column corresponds to

537 the code in Fig. 1.

\begin{tabular}{|c|c|c|c|c|c|c|c|c|}
\hline Region & Study Sites & Code & $\begin{array}{c}\text { Sampling } \\
\text { year }\end{array}$ & Treatment & Vegetation & Cover & $\begin{array}{l}\text { Insecticid } \\
\text { e pressure }\end{array}$ & $\begin{array}{l}\text { Leaf } \\
\text { litter }\end{array}$ \\
\hline \multirow{14}{*}{ 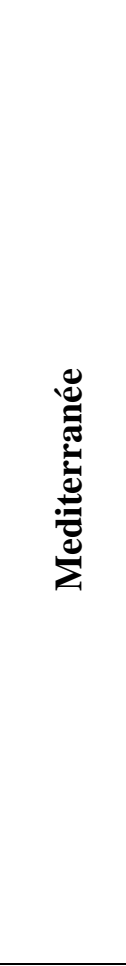 } & Beauchamp & $\mathrm{BC}$ & 2009 & Treated & $\begin{array}{c}\text { Bulrush } \\
\text { bed }\end{array}$ & low & 3 & low \\
\hline & Cabane du Roc & CR & 2009 & Treated & Salt marsh & low & 8 & null \\
\hline & Caisse de Mort & $\mathrm{CM}$ & 2009 & Treated & Salt marsh & low & 12 & null \\
\hline & Les Enfores 1 & EN & 2009 & Treated & Salt marsh & low & 3 & null \\
\hline & Manade Blattière & MBl & 2009 & Treated & Meadow & low & 5 & low \\
\hline & Mas Badet & MB & 2009 & Untreated & Salt marsh & low & 0 & null \\
\hline & Mas d'Icard & MI & 2009 & Untreated & Reed Bed & dense & 0 & low \\
\hline & Tour Carbonnière & $\mathrm{TC}$ & 2009 & Treated & Salt marsh & low & 2 & null \\
\hline & $\begin{array}{l}\text { Triangle aux } \\
\text { Anes }\end{array}$ & TA & 2009 & Treated & Rush bed & dense & 2 & null \\
\hline & La Carbonelle & CA & 2010 & Treated & Meadow & low & 3 & null \\
\hline & La Douane & DO & 2010 & Treated & Rush bed & dense & 25 & null \\
\hline & Les Enfores 2 & EN & 2010 & Treated & Reed bed & dense & 6 & low \\
\hline & Embouchac & EM & 2011 & Treated & Salt marsh & low & 10 & null \\
\hline & Les Enfores 2 & EN & 2011 & Treated & Reed bed & dense & 2 & low \\
\hline \multirow{16}{*}{ 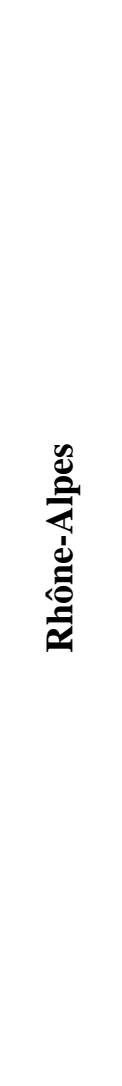 } & Albens 1 & $\mathrm{AL}$ & 2010 & Untreated & Forest & dense & 0 & high \\
\hline & Albens 2 & $\mathrm{AL}$ & 2010 & Untreated & Forest & dense & 0 & high \\
\hline & Albens 3 & $\mathrm{AL}$ & 2010 & Treated & Forest & dense & 6 & high \\
\hline & Albens 4 & $\mathrm{AL}$ & 2010 & Treated & Forest & dense & 6 & high \\
\hline & Château-Gaillard & $\mathrm{CG}$ & 2010 & Treated & Forest & dense & 5 & high \\
\hline & Etremblières & ET & 2010 & Untreated & Reed bed & dense & 0 & low \\
\hline & Gaillard 1 & GA & 2010 & Treated & Forest & dense & 6 & high \\
\hline & Gaillard 2 & GA & 2010 & Treated & Forest & dense & 5 & high \\
\hline & La Verpillière & VE & 2010 & Treated & Forest & dense & 6 & high \\
\hline & Reignier & $\mathrm{RE}$ & 2010 & Untreated & Forest & dense & 0 & high \\
\hline & $\begin{array}{l}\text { Saint-Maurice- } \\
\text { de-Gourdans }\end{array}$ & SMG & 2010 & Treated & Forest & dense & 5 & high \\
\hline & $\begin{array}{l}\text { Saint-Maurice- } \\
\text { de-Remens }\end{array}$ & SMR & 2010 & Untreated & Forest & dense & 0 & high \\
\hline & Scentrier 1 & $\mathrm{SC}$ & 2010 & Treated & Forest & dense & 5 & high \\
\hline & Scentrier 2 & $\mathrm{SC}$ & 2010 & Treated & Forest & dense & 4 & high \\
\hline & Solaize & SO & 2010 & Treated & Forest & dense & 2 & high \\
\hline & Ternay & TE & 2010 & Untreated & Forest & dense & 0 & high \\
\hline
\end{tabular}


539 Table 2. Analysis of the deviance table of GLM (quasi-poisson family, link=log) fitting

540 CFU counts per gram in the field samples to two factors added sequentially (first to last):

541 Treatment modality (treated or untreated) and Vegetation type (salt marsh, meadow,

542 bulrush bed, rush bed, reed bed and forest). Chi-square $p$ values indicate the level of

543 significance of the various factors in the model as compared to the Null model (no effect

544 included); $\boldsymbol{p}$ values $<\mathbf{0 . 0 5}$ are in bold characters

545

\begin{tabular}{lccc}
\hline \multicolumn{1}{c}{ Factor } & Df & Deviance & $\begin{array}{c}\text { Chi-square } p \\
\text { value }\end{array}$ \\
\hline Null & 519 & 4452895 & \\
Treatment & 1 & 338419 & $\mathbf{4 . 5 2 9 ~ 1 0}$ \\
Vegetation type & 5 & 393681 & $\mathbf{1 . 6 5 2 ~ 1 0}^{-\mathbf{3}}$ \\
Treatment $\times$ Vegetation type & 2 & 8238 & 0.816 \\
\hline
\end{tabular}


550 Table 3. Analysis of the deviance table of GLM (quasi-poisson family, link=log) fitting 551 CFU counts per gram in the field samples to three factors added sequentially (first to 552 last): Insecticide pressure (expressed as the number of treatment/year/study site), 553 Vegetation cover (low or dense); Leaf litter (null, low, and high). Chi-square $p$ values 554 indicate the level of significance of the various factors in the model as compared to the 555 Null model (no effect included); $\boldsymbol{p}$ values $<\mathbf{0 . 0 5}$ are in bold characters

556

\begin{tabular}{lccc}
\hline \multicolumn{1}{c}{ Factor } & Df & Deviance & $\begin{array}{c}\text { Chi-square } p \\
\text { value }\end{array}$ \\
\hline Null & 519 & 4452895 & \\
Insecticide pressure & 1 & 245 & 0.899 \\
Vegetation cover & 1 & 78212 & $\mathbf{0 . 0 2 4}$ \\
Leaf litter & 2 & 60449 & 0.141 \\
Vegetation cover $\times$ Leaf litter & 1 & 56730 & 0.054 \\
Insecticide pressure x Leaf litter & 2 & 759338 & $\mathbf{1 . 9 8 ~ 1 0}^{-\mathbf{1 1}}$ \\
Insecticide pressure $\times$ Vegetation cover & 1 & 16969 & 0.293 \\
Insecticide pressure x Leaf litter x Vegetation & 1 & 112823 & $\mathbf{6 . 8 ~ 1 0}^{-3}$ \\
cover & & & \\
\hline
\end{tabular}




\begin{tabular}{lccc}
\hline Factor & Chisq & Df & $\begin{array}{c}\text { Chi-square } p \\
\text { value }\end{array}$ \\
\hline Date & 48.2012 & 9 & $\mathbf{2 . 3 4 2 e - 0 7}$ \\
Substrate & 4.4208 & 1 & $\mathbf{0 . 0 3 5 5}$ \\
Salinity & 1.0788 & 1 & 0.2990 \\
Water height & 0.0993 & 1 & 0.7527 \\
Date $\times$ Substrate & 3.3583 & 9 & 0.9484 \\
Date $\times$ Salinity & 4.3859 & 9 & 0.8842 \\
Date $\times$ Water height & 15.3338 & 9 & 0.0822 \\
Substrate $\times$ Salinity & 0.0304 & 1 & 0.8616 \\
Substrate $\times$ Water height & 0.0063 & 1 & 0.9366 \\
Date $\times$ Substrate $\times$ Salinity & 0.3544 & 9 & 0.9999 \\
Date $\times$ Substrate $\times$ Water height & 1.4954 & 9 & 0.9972 \\
\hline
\end{tabular}

\begin{tabular}{lccc}
\hline Factor & Chisq & Df & $\begin{array}{c}\text { Chi-square } p \\
\text { value }\end{array}$ \\
\hline Date & 48.2012 & 9 & $\mathbf{2 . 3 4 2 e - 0 7}$ \\
Substrate & 4.4208 & 1 & $\mathbf{0 . 0 3 5 5}$ \\
Salinity & 1.0788 & 1 & 0.2990 \\
Water height & 0.0993 & 1 & 0.7527 \\
Date $\times$ Substrate & 3.3583 & 9 & 0.9484 \\
Date $\times$ Salinity & 4.3859 & 9 & 0.8842 \\
Date $\times$ Water height & 15.3338 & 9 & 0.0822 \\
Substrate $\times$ Salinity & 0.0304 & 1 & 0.8616 \\
Substrate $\times$ Water height & 0.0063 & 1 & 0.9366 \\
Date $\times$ Substrate $\times$ Salinity & 0.3544 & 9 & 0.9999 \\
Date $\times$ Substrate $\times$ Water height & 1.4954 & 9 & 0.9972 \\
\hline
\end{tabular}

Table 4. Analysis of the deviance table of GLMM fitting Bti CFU counts to four explanatory factors: Date: sampling dates; Substrate: inorganic substrate, and substrate with leaf litter; Salinity: water salinity $\left(40\right.$ g.L $L^{-1}$ or 0 g.L $\left.{ }^{-1}\right)$; Water level: maintained or fluctuating. Microcosm effect was included in the model as a random effect (experiment 1 of microcosms). Chi-square $p$ values indicate the level of significance of the various factors in the model; $p$ values $<0.05$ are in bold characters. 
Table 5. Analysis of the deviance table of GLMM model fitting Bti CFU counts to four fixed explanatory factors (experiment 2 of microcosms). Date: sampling dates; Substrate: substrate with leaf litter and water only; Larvae: with or without mosquito larvae; Concentration: Bti at 2.5 or $12.5 \mu \mathrm{L} . \mathrm{L}^{-1}$. Microcosm effect was included in the model as a random effect. Chi-square $p$ values indicate the level of significance of the various factors in the model; $p$ values $<0.05$ are in bold characters

\begin{tabular}{lccc}
\hline Factor & Chisq & Df & $\begin{array}{c}\text { Chi-square } p \\
\text { value }\end{array}$ \\
\hline Date & 98.1028 & 9 & $<\mathbf{2 . 2 e - 1 6}$ \\
Substrate & 0.2787 & 1 & 0.5975 \\
Larvae & 15.6950 & 1 & $\mathbf{7 . 4 4 2 ~ 1 0}$ \\
Concentration & 0.8333 & 1 & 0.3613 \\
Date $\times$ Substrate & 48.1673 & 9 & $\mathbf{2 . 3 7 7 ~ 1 0}$ \\
Date $\times$ Larvae & 12.4196 & 9 & 0.1907 \\
Date $\times$ Concentration & 36.5869 & 9 & $\mathbf{3 . 1 1 8 ~ 1 0}$ \\
Substrate $\times$ Larvae & 2.6577 & 1 & 0.1030 \\
Substrate $\times$ Concentration & 7.0542 & 1 & $\mathbf{0 . 0 0 7 9}$ \\
Larvae $\times$ Concentration & 0.0372 & 1 & 0.8471 \\
Date $\times$ Substrate $\times$ Larvae & 2.9440 & 9 & 0.9665 \\
Date $\times$ Substrate $\times$ Concentration & 6.8954 & 9 & 0.6480 \\
Date $\times$ Larvae $\times$ Concentration & 3.0020 & 9 & 0.9642 \\
Substrate $\times$ Larvae $\times$ Concentration & 0.3705 & 1 & 0.5427 \\
Date $\times$ Substrate $\times$ Larvae $\times$ & 0.5458 & 9 & 0.9999 \\
Concentration & & & \\
\hline
\end{tabular}




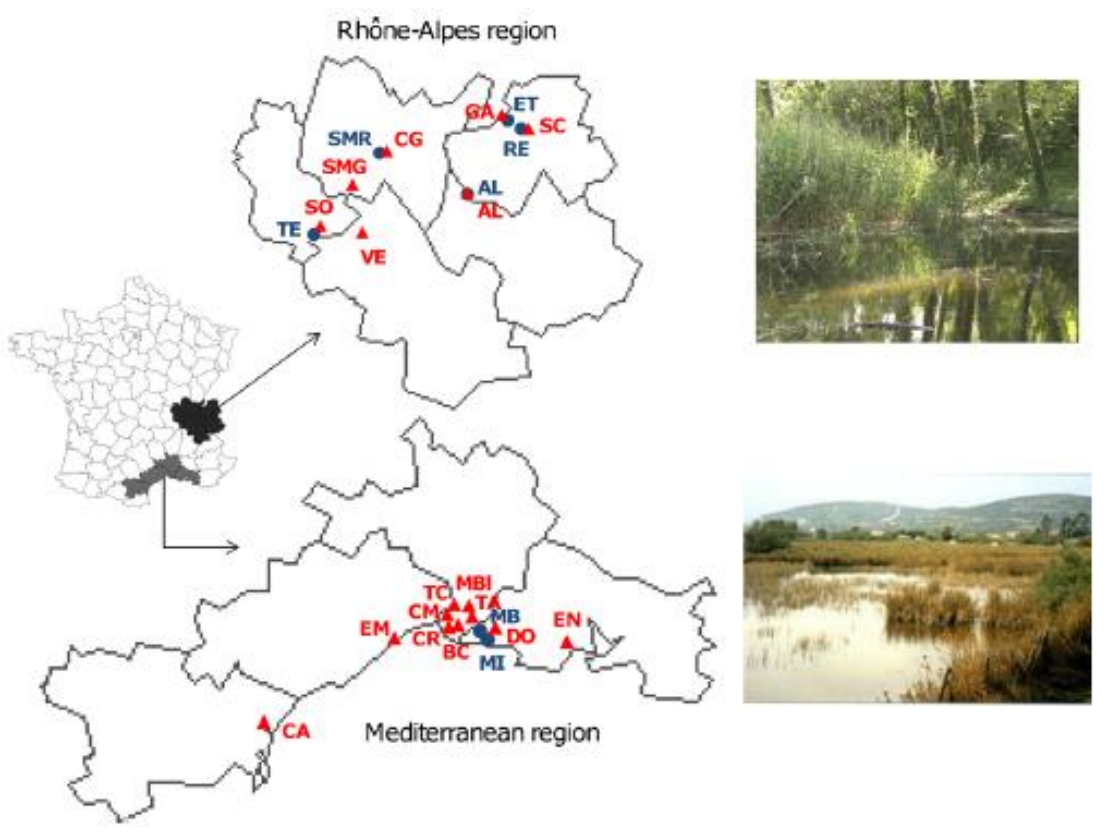

Fig. 1. Localization of the mosquito breeding sites sampled, including 16 in the French Rhône-Alpes region (upper part of the figure) and 12 in the Mediterranean region (lower part of the figure). Some sites were geographically so close that they cannot be distinguished on the map (eg, AL, EN) but they differed for the number of treatments and/or vegetation type. The treated sites are indicated by a red triangle and the untreated sites by a blue circle. The correspondence of the sites names is indicated in the Table 1. A picture of a representative breeding site (i.e. woodland ponds enriched in organic matter versus open areas of salt water on a sandy substrate for the Rhône-Alpes and Mediterranean region, respectively) is shown at the right part for each region. 
experiment 1

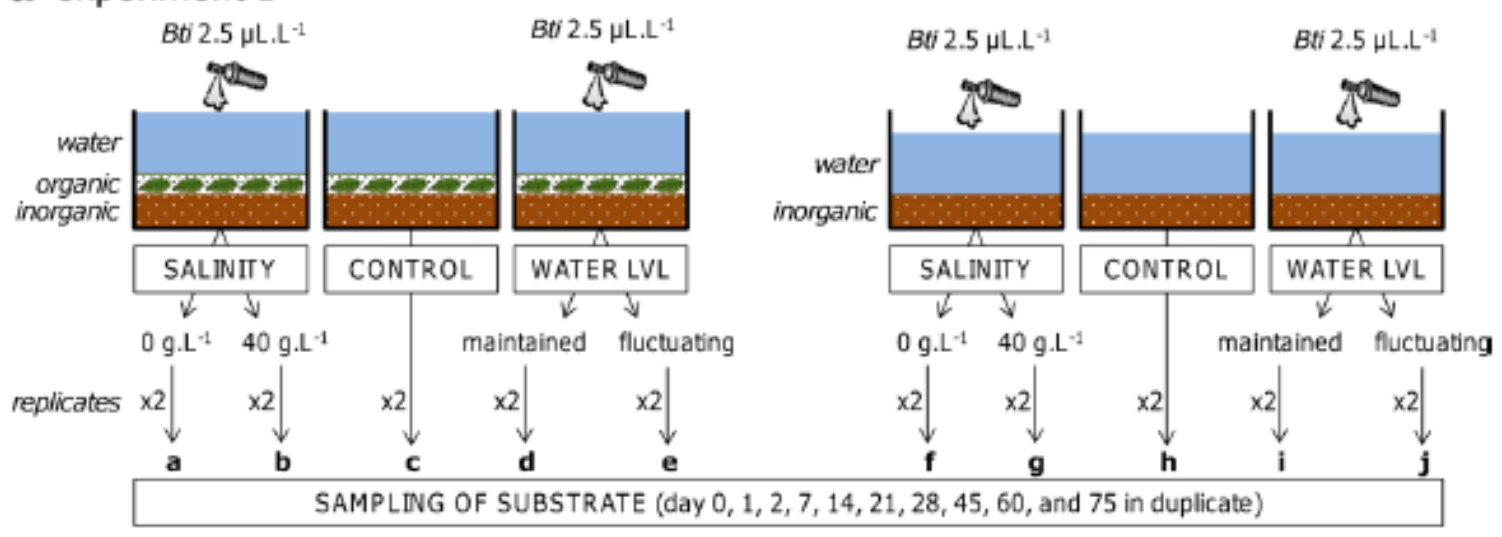

b experiment 2
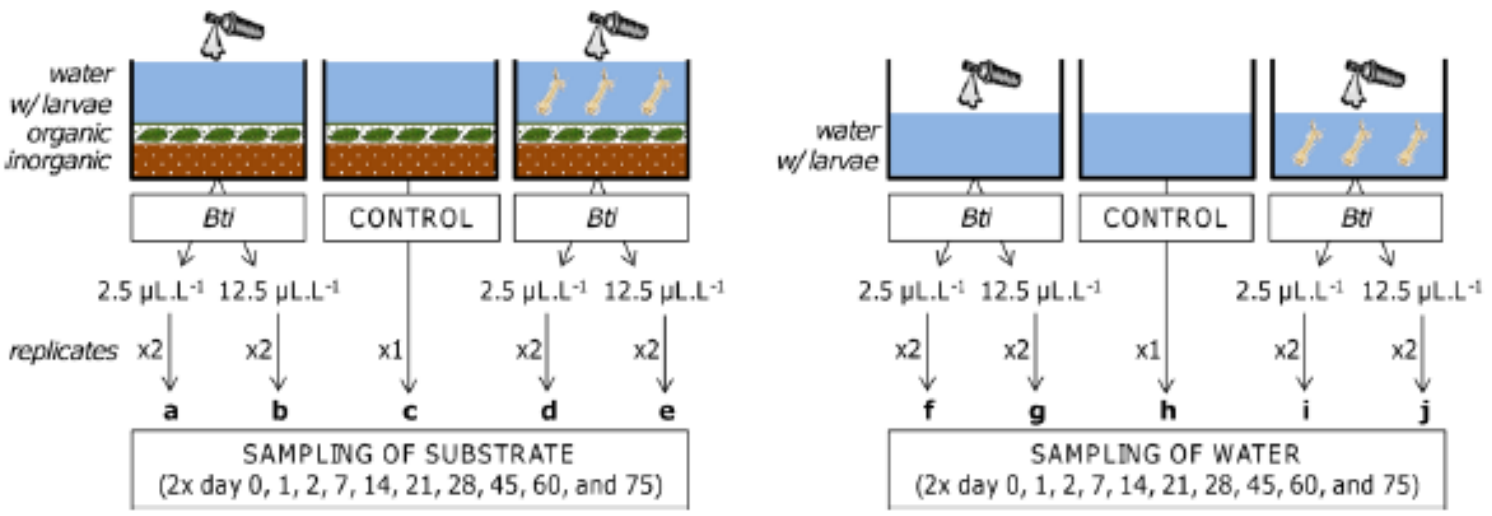

Fig. 2. Illustration of the experimental design of microcosms for evaluating the influence of (A) the presence of organic matter, the salinity (conditions a,b,f,g), the water level fluctuation (conditions d,e,i,j) and (B) the presence of larvae, with organic substrate (conditions a-e) or in water only (conditions $\mathrm{f}-\mathrm{j}$ ), on the fate of Bti. Commercial Bti was sprayed at a concentration of $2.5 \mu \mathrm{L} . \mathrm{L}^{-1}$ (experiment 1 (A) and experiment 2 (B), conditions a,d,f,i) or $12.5 \mu \mathrm{L} . \mathrm{L}^{-1}$ (experiment 2 (B), conditions b,e,g,j). Controls consisted in untreated aquaria (conditions c and $\mathrm{h}$ ). All conditions were performed in duplicate, except for controls in experiment 2 . Ten sampling were performed in duplicate for each condition and each experiment. 

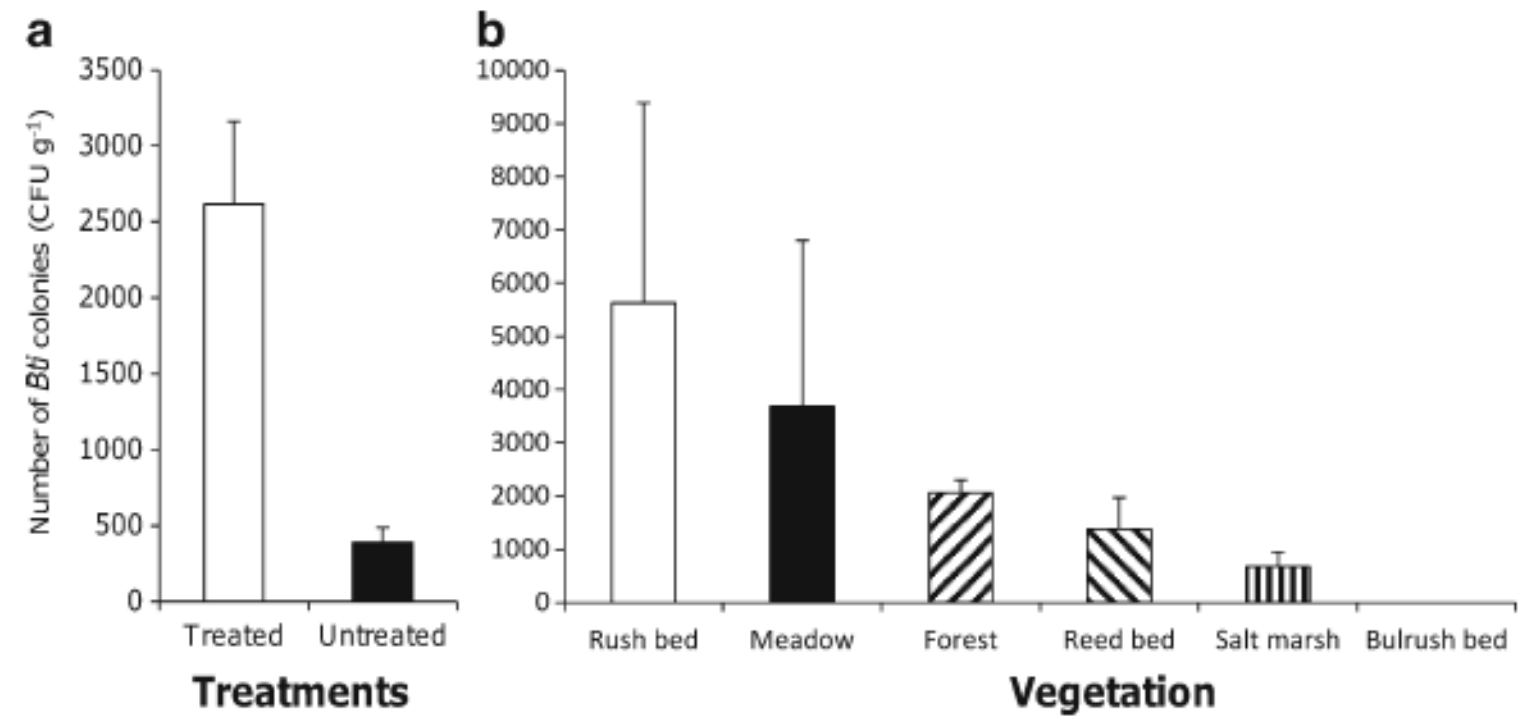

600

601

Fig. 3. Quantity of Bti spores (mean $\pm \mathrm{SE}$ ), expressed as colony forming unit (CFU) per gram

602 of soil, in function of A. Bti treatment (Mann-Whitney test, $p<0.001$ ) and B. Main vegetation 603 type (Kruskall-Wallis test, $p<0.001$ )

604
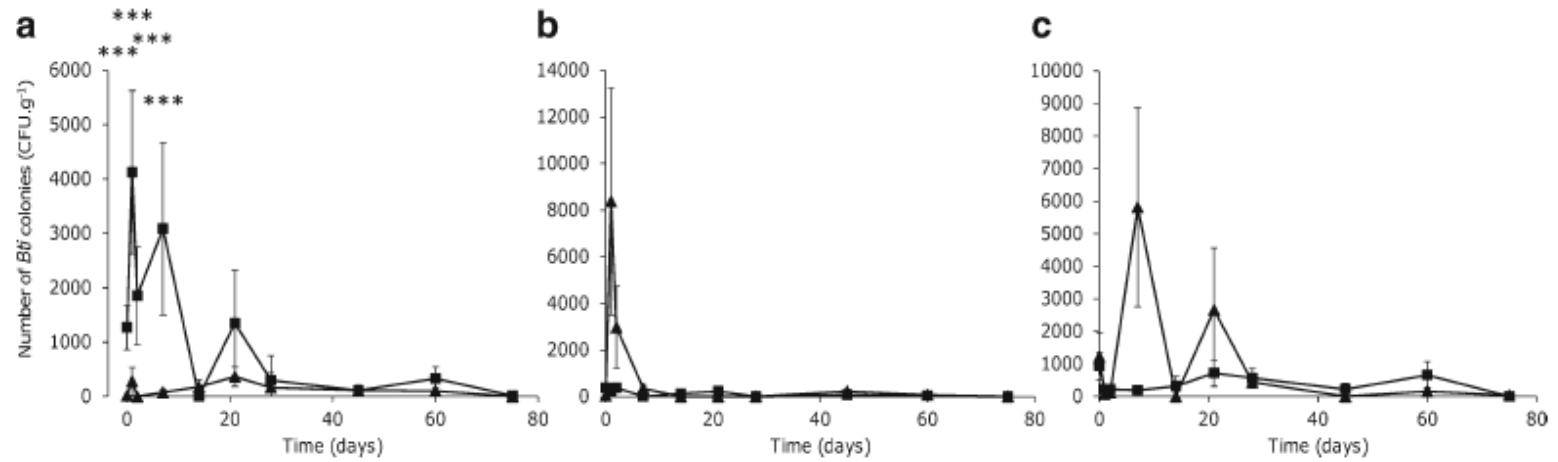

605

606

607

608

609

610

611

612

613

614

615

616

617

Fig. 4. Quantity of Bti spores (mean \pm SE), expressed as colony forming unit per gram of soil, in function of three parameters (experiment 1 of microcosms). A. Influence of the substrate type on Bti abundance (inorganic, triangles; organic, squares). B. Influence of the salinity on Bti abundance ( 0 g.L $\mathrm{L}^{-1}$ of salt, triangles; $40 \mathrm{~g} . \mathrm{L}^{-1}$, squares). C. Influence of the water level on $B t i$ abundance (fixed, triangles; fluctuating, squares). Mann-Whitney tests for each sampling date and for each modality: ***: $p<0.001$. 


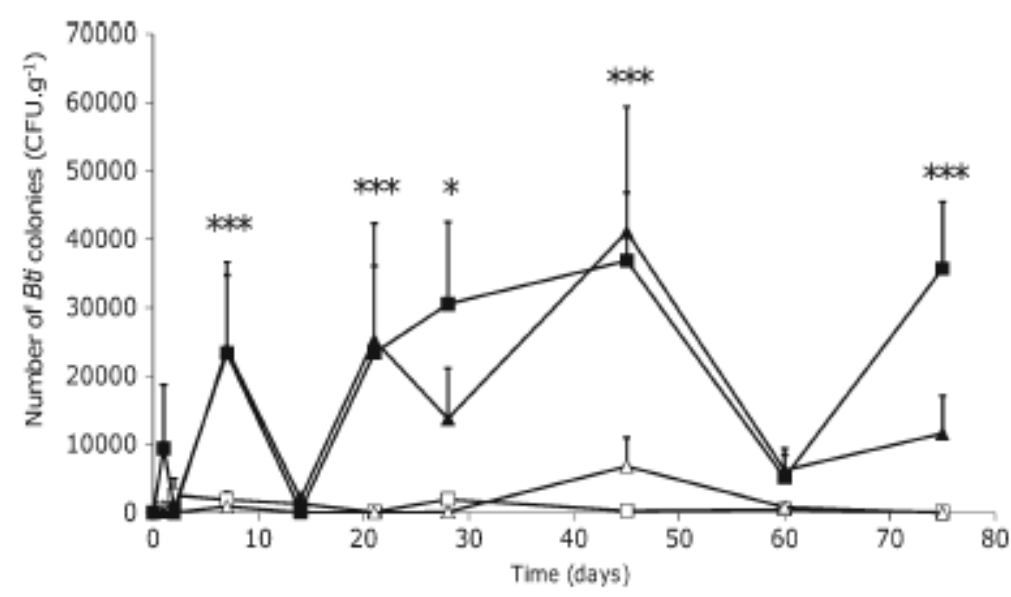

619 Fig. 5. Quantity of Bti spores (mean \pm SE), expressed as colony forming unit per gram of 620 substrate, in the microcosms treated with Bti at 2.5 (triangle) and $12.5 \mu \mathrm{L} . \mathrm{L}^{-1}$ (square), with 621 (dark) or without (white) Ae. aegypti larvae (experiment 2 of microcosms). Kruskall-Wallis 622 test: $*: p<0.05$; ***: $p<0.001$. 